\title{
The effect of Word Part Strategy Instruction on Moroccan EFL University Students' Word knowledge
}

\author{
Mounir Harraqi \\ Faculté des Sciences de l'Éducation - Mohamed V University, Rabat
}

\begin{abstract}
The study aims to investigate the impact of word part strategy on L2 vocabulary acquisition. The purpose of the current study is to examine how word part strategy can help students to understand words and facilitate vocabulary acquisition. Fifty students from a Moroccan public engineering school contributed in the study. All participants were given vocabulary pre-test, short lectures about word-formation rules and two vocabulary tests. The results show that word part strategy is helpful in understanding words and facilitating vocabulary acquisition.
\end{abstract}

Keywords: Affix Knowledge; Vocabulary Acquisition; Word Part Strategy

\section{Introduction}

The focus on vocabulary in second language (henceforth, L2) and foreign language (henceforth, FL) learning and teaching is not an exclusively current concern. Many psychologists, linguists and language teachers have been interested in vocabulary learning strategies for a long time (Levenston, 1979). The best example of earlier focus on vocabulary in L2 and FL teaching could be the Grammar Translation Method that advocates the learning of lists of vocabulary items with multiple-choice equivalents. Nevertheless, the development of modern applied linguistics, both theoretically and empirically, has directed researchers towards pointing out the crucial role of vocabulary in L2 and FL learning. Traditionally, vocabulary learning strategy research has concentrated on the size of the lexicon and the number of words that are learned in different L2 and FL contexts. Moreover, a number of studies have revealed students' vocabulary learning strategies (henceforth, VLS) and their frequency of use along with the effect of genderon theiruse. However, and to the researcher' best knowledge, therehas been only one research study which investigates the impact of word part strategy on L2 vocabulary acquisition ( Henceforth, WPS) and it was carried out in Swedish context. For this reason, this study aims at contributing to the ongoing L2 research in the field of VLS, especially in the Moroccan EFL university learners. 


\section{International Conference on Advanced Research in SOCIAL SCIENCES}

March 7-9, 2019, London - United Kingdom

\section{Review of the Literature}

Research on learning strategies has been exhilarated by two closely intertwined disciplines: cognitive psychology and second language acquisition. In fact, it is cognitive that has inspired learning strategy research. Research in cognitive psychology was experimental and orientedtowards training learners to acquire strategies. In this field, the question was posed as why there are some individuals very effective in learning. According to Anderson's (1985) model of mental operation in learning a skill to language learning, two kinds of knowledge are involved in the acquisition skills: declarative knowledge and procedural knowledge. The former is static factual knowledge, or what learners know about a domain, whereas the latter, known as dynamic information, is the faculty to understand and generate language or apply knowledge of rules to solve a problem without conscious application of these rules.

Nevertheless, in the field of SLA, researchers have conducted research on learning strategies independently of cognitive psychologists. For instance, early research in the SLA field was descriptive. Within this field, Rubin (1975) and Stern (1975) made their attempts to describe what they called: "good language learner strategies"and they described, classified, and reported the activities performed by this type of language learners. Building on their research, Rubin (1981) and Naiman, Frhlish, Stern and Rigney (1978) proposed classification schemes of language learning strategies.

However, since little research has been done regarding learning strategies, It has been difficult to distinguish "which strategies are fundamental for learning which ones be more useful to other learners, and which should be combined with others to maximize learning effectiveness' '(O'Malley and Chamot, 1990).

\section{Definition of a Language Learning Strategies}

Several researchers define LLSs according to their theoretical background. For instance, Rubin (1987) defines learning strategies as "any set of operations, plans, or routines, used by learners to facilitate the obtaining, retrieval, storage and use of information" (P.19). Rigney (1978) before Rubin (1987) defines in bread terms LLSs "a set of operations used by the learner toaid the acquisition, storage and retrieval of information". Lafer, Stern(1983,p.405)refers to LLSs as particular forms of observable learning behavour, more or less consciously employed by the learner." In 1992, Stern states in somewhat specific terms "the concept of learning strategy is dependent on the assumption that learners consciously engage in activities to achieve certain goals and learning strategies can be regarded as broadly conceived intentional directions and learning techniques."(1983).

In Oxford's (1990) definition, some student-intended goals are evident. Among these goals is that strategies help learners facilitate and accelerate the learning process and make of learning an enjoyable task which is at the same time self-directed and effective. Strategies with such goals can only be transferable to new situations of learning as Oxford put it. This definition, thus, stretches the list of goals set by O'Malley and Chamot (1990).

\section{Strategy Use and Vocabulary}

Plenty of studies have been carried out on vocabulary learning and how they can improve students' retention of new words in a language or improve their understanding of written as well as spoken text 
March 7-9, 2019, London - United Kingdom

Among the first studies which explored change in vocabulary learning strategy use over time was the one conducted by Schmitt. (1997). The participant revealed in their self-reports that dependence on written repetition, word spelling, word lists, flashcards, and textbook vocabulary activities declined as they became more proficient in the language. Simultaneously, however, there was a rise in the participants' use of bilingual dictionaries, guessing from context, asking teachers for paraphrase or as a synonymy, analysis of parts of speech, imaging words meaning and connecting words to personal experience. The same finding that more proficient learners resorted to the use of more sophisticated vocabulary learning strategies was reached by Fan (2003) in his seminal work on 1067 university students in Hong Kong. Besides, the study conducted by Celik and Topas (2010) together with that of Liu (2010) confirmed that vocabulary strategy y use differed according to students' language levels and their rating of strategy helpfulness.

From the perspective of strategy training, many researchers found that teaching a variety of vocabulary learning strategies is effective in improving the vocabulary seize of students and facilitating language learning in general, Ahari, Sadegholi and Araghi (2014).

\section{The importance of Strategy Training}

In the literature, different terms are used to refer to strategy training. For instance, some researchers such us Oxford (1990) and Cohen(2002)favorthe term 'strategy training' whileEllis and Sinclair (1989) andEllis (1997) use 'learner training' and still others like Chamot (2004) prefer the term 'strategy instruction'. Despite the divergence in terminology, all researchers agree on the fact that strategy training (or instruction) provides learners wide range of strategies that help them learn the language more easily and effectively and, consequently, achieve success and autonomy in learning within and outside the classroom environment.

\section{a. Word Part Strategy}

According to Nation, word part strategy consists of two steps:

1. Break the unknown word into parts. This step requires learners to be able to recognise prefixes and suffixes when they occur in words.

2. Relate the meaning of the word parts to the meaning of the word. This step requires the learners to know the meanings of the common word parts. This step also requires the learners to be able to re-express the dictionary definition of a word to include the meaning of its prefix, and if possible its stem and suffix. (p. 278)

3.

In paraphrasing Nation, the first requirement to obtain the basic knowledge of using word part strategy, is having the ability to break the unknown parts into its parts. For Instance, the word unforgettable consists of three parts, i.e. un-, forget, and -able. Before using the strategy, learners must recognize the word parts. The second step recommended by Nation involves the advanced knowledge of using the strategy, because learners don't only need to know the meanings of each part, but must also have the ability to re-express the meaning of the new word by using affix knowledge and then connect the meaning of the word parts with the dictionary meaning of the whole word to facilitate understanding.

Nation believes that word part strategy could be used for both high and low frequency words, however, it takes a long time to learn the meaning of affixes and learn how to re-express meanings (p.280). 


\section{International Conference on Advanced Research in SOCIAL SCIENCES}

March 7-9, 2019, London - United Kingdom

\section{Research Methodology \\ 1 Research questions and hypothesis}

The present study attempts to answer the following questions:

1- What is the vocabulary size of third-year university students at the Higher

National School of Mines?

2- What is the impact of word parts vocabulary learning strategy on second language vocabulary learning?

3- Is there a difference between the students of the experimental group who have words parts strategy instruction and those in the control group?

To answer the research questions above, the following hypothesis will be tested: H1 . Vocabulary learning will increase after the use of word parts strategy.

$\mathrm{H} 2$. There will be a positive effect of word parts strategy instruction on the experimental group than the control one.

\section{Participants}

The study was conducted on third-year university students enrolled in the Higher National School of Mines (ENSMR) in Rabat. The age is ranging from 19 to 22. All participants' specialty is engineering. As for their English proficiency level, students are at the pre-intermediate level based on their scores in a placement test given at the beginning of the year. They are exposed to English for 5 years ( 3 at high school and 2 while studying in preparatory classes before enrolling in ENSMR). Technically, this is their sixth year of English exposure.

\section{Research Instruments}

The study consists of a pre-test, a lecture about word-formation rules and two vocabulary post-tests. The pre-test (Vocabulary Levels Test (VLT): Nation (2001) created the form of the pre-test. The test consists of five level. The first level contains the 1000 most frequent words;

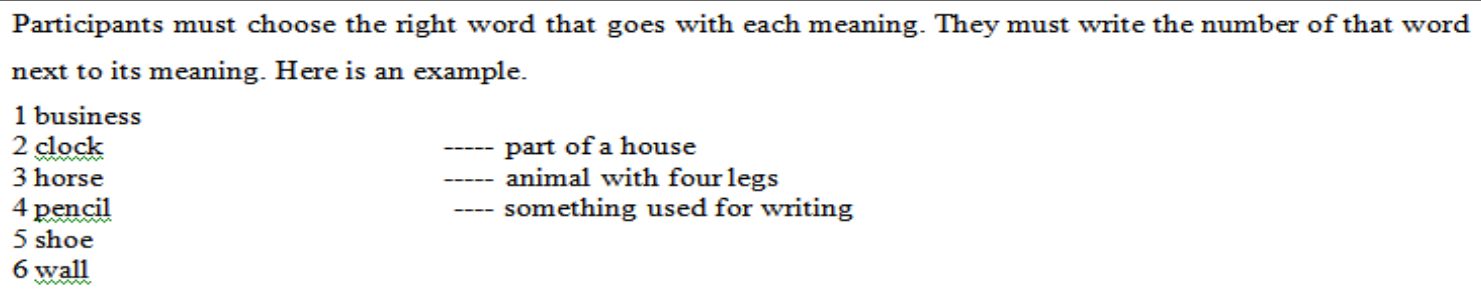

Figure 1- VLT item [13]

the second level contains the second most frequent 1000 word families and so on. At each level, there are 60 words (in groups of 6) and 30 definitions (in groups of 3). The 2,000-word and 3,000 - word levels contain the high frequency words that all learners need to know to function efficiently in English. The VLT is used in this study to make sure that both the experimental and control groups are homogeneous in terms of vocabulary size. (see figure 1) 


\title{
International Conference on Advanced Research in SOCIAL SCIENCES
}

\author{
March 7-9, 2019, London - United Kingdom
}

Brief lecture about word-formation rules: Ten brief lectures about word part strategy and basic word-formation knowledge were given during the period of three month after the pre-test as the subjects needed to acquire basic knowledge about word-formation as well as the meaning of affixes in order to understand how to apply word part strategy. The meanings of the ten selected affixes were taught in the lecture and common words using these affixes were analyzed with the aid of word part strategy (see figure 2). All the subjects were present and were thus given the same information. (see figure 2)

\section{1. -ion: the suffix attached to verbs ending in -ate to form nouns \\ Create: bring (something) into existence \\ Creation: the action or process of bringing something into existence}

2. -ize: the suffix forms verbs

Modern: relating to the present or recent times as opposed to the remote past

Modernize: adapt (something) to modern needs or habits

\section{Figure 2-Treatement (item1)}

Post- tests: Two vocabulary tests were given after the lecture (see figure 3 and 4). There were twenty unknown words in Test A, and the meaning of the roots was given. The subjects were required to use word- formation rules and knowledge of affixes to explain the meaning of the words in English to see if they could use the meaning of each part to define the words. The subjects were required to hand in Test $\mathrm{A}$ and were then given Test $\mathrm{B}$ in the following session. The twenty words to be tested in Test B were the same ones in Test A. The subjects were asked to match the correct meaning of twenty words from forty choices, which had been divided into four groups (ten words in each group). There was a balance between the numbers of nouns and verbs (or adjectives) in each group. Words that can be easily confused were also put into the same group. The aim of the two tests was to investigate whether students can use word part strategy to work out the meaning of a word using affixes and whether the word part strategy facilitates vocabulary learning.

Test A: Ss were given 20 unknown words (the meaning of the roots was given.

Ex. Hydrate: cause to absorb water.

Dehydrate:

Plausible: (of an argument or statement) seeming reasonable or probable.

Implausible:

Figure 3- post-test A 


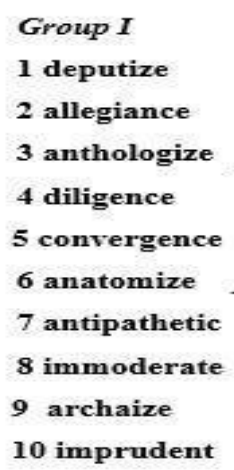

Figure 4-post-test B

\section{Data Analysis and discussion}

\section{Vocabulary level before the treatment}

The data collected was analyzed using SPSS 22.0. The results of the three tests were compared, and the basic statistics for the tests are listed in the tables below. Table 1 shows the results of each level of the VLT pre-test.

\section{Results for Question 1}

Dealing with the experimental group, the best results are attained in the 2000 word level where the participants know on average 26 words out of 30 . As the level goes up, the average drops. Overall, the three levels participants knew 68 words $(75 \%)$ out of the 90 words that make up the three levels. According to Nation (2001) if students know the 2000 most frequent words of English, they in fact know $81 \%$ of the words on any page.

Table 1: Results of VLT Pre-test ( $N=25)$ (experimental group)

\begin{tabular}{|r|r|l|}
\hline Level & Mean & \\
\hline 2000 & 25.53 & 2.13 \\
\hline 3000 & 23.36 & 3.14 \\
\hline 5000 & 19.14 & 6.6 \\
\hline Total & 68.03 & 11.87 \\
\hline
\end{tabular}

As for the control group, similar to the experimental group, the best results are attained in the 2000 word level where the participants know on average 25 words out of 30 . As the level goes up, the average drops. Overall, the three levels participants knew 67 words (74\%) out of the 90 words that make up the three levels.

Table 2: Results of VLT Pre-test $(N=25)$ (control group)

\begin{tabular}{|r|r|r|}
\hline Level & Mean & SD \\
\hline 2000 & 24.16 & 2.02 \\
\hline 3000 & 22.51 & 2.13 \\
\hline 5000 & 20.66 & 3.3 \\
\hline Total & 67.33 & 7.45 \\
\hline
\end{tabular}


Table 1 and 2 reveal that the experimental group performed nearly the same as the control group in the Vocabulary Levels Test. The scores of the participants suggest, according to Nation (2000), that the students of both the experimental and control groups were within the range of intermediate EFL university students in terms of vocabulary size. In other words, both groups are homogeneous in their vocabulary level.

\section{The effect of word parts strategy after the treatment}

To find out whether word part strategy is an effective method for helping students to understand new words and facilitate vocabulary learning, ten participants were given two tests each (Tests A and B). The results are displayed in the following tables.

\section{Results for Question 2}

\subsection{Post-tests results}

The purposes of Tests A and B are to answer the research questions (2) whether word part strategy can help students understand new words and (3) whether word part strategy can help facilitate vocabulary acquisition. Immediately after the short lecture about affix knowledge and word part strategy, both the experimental and control groups took two tests. The results are shown in Table 3 below.

\subsection{Analysis of Test A and B}

Dealing with the experimental group, it was demonstrated in Test A that the meaning of 16 out of twenty words on the average could be worked out. This result complies with Nation's theory that word part strategy can help students to learn unfamiliar words by connecting the words to known word parts (p. 264). However, the results of Test A are not sufficiently conclusive to demonstrate that knowing a word necessarily involves knowing the members of its word family, as many researchers have suggested (Bauer \& Nation, 1993; Nation, 2001). The result of Test B is roughly the same as the result of Test A, i.e. 15 words were known out of the twenty unknown words. The data suggests that the process of recognizing the meanings of the unfamiliar words by using affix knowledge and the meaning of roots helps students to remember the meaning of the words and thus facilitate vocabulary learning. The reasons for and implications of this result are discussed below.

Dealing with the control group as being illustrated in Test A the meaning of only 7 words out of twenty words were grasped. This result should be kept in mind taking into consideration that the 20 tested items are unfamiliar to the students' knowledge and most of these words are advanced ones. The results of the control group in Test B are not very different from their results in Test A. In this sense, out of the twenty unknown words, the students were only able to define the meaning of 9 words. While there are many contributory factors, an important factor is that many roots of the words were unfamiliar to the students at the time of taking the test.

The results of Test A and B, therefore, answers the RQ2; there is an improvement of learners (the experimental group) in retaining Test A and B words and confirm the positive impact of words part strategy on second language vocabulary learning. The results reject the null hypothesis and accept the alternative one. The results which fit the alternative hypothesis, suggest that after receiving the treatment via the training on word part strategy leaners in the experimental group showed improvement and were better in retaining and defining L2 words than learners in the control group who did not receive any training on WPS. 
March 7-9, 2019, London - United Kingdom

Table 3: Overall View of Tests Results (the post-tests)

\begin{tabular}{|r|r|r|r|r|r|}
\cline { 2 - 6 } \multicolumn{1}{c|}{} & Item & $\begin{array}{r}\text { Total } \\
\text { Answers* }\end{array}$ & $\begin{array}{r}\text { Total } \\
\text { Right } \\
\text { Answers }\end{array}$ & Percentage & Average** \\
\hline \multirow{2}{*}{ Experimental Group } & Test A & 500 & 408 & $83.20 \%$ & 16.64 \\
\cline { 2 - 6 } & $\begin{array}{r}\text { Test } \\
\mathrm{B}\end{array}$ & 500 & 416 & $81.60 \%$ & 16.32 \\
\hline \multirow{2}{*}{ Control Group } & $\begin{array}{r}\text { Test } \\
\mathrm{A}\end{array}$ & 500 & 186 & $37.20 \%$ & 7.44 \\
\cline { 2 - 6 } & $\begin{array}{r}\text { Test } \\
\mathrm{B}\end{array}$ & 500 & 214 & $46.6 \%$ & 9.32 \\
\hline
\end{tabular}

Each student answered twenty questions, so there were two hundred $(25 \times 20)$ answers altogether in each test.

\section{Results for Question 3}

Research question 3 focuses on the difference between the students of the experimental group who have words parts strategy instruction and those in the control group.

As the table 3 indicates and by comparing the means of the experimental and control groups, the effect of word part strategy on the experimental group. As being illustrated in the table below the $\mathrm{T}$ (38) equals 2.514 and the two-tailed $\mathrm{P}$ value equals 0.0163 which is less than 0.05 . Therefore, by conventional criteria, this difference is considered statistically significant and the null hypothesis is rejected. Hence, there is a difference between the experimental group and control group.

Table 4: Overall View of Tests Results ( T-Test): Test A

\begin{tabular}{|c|c|c|c|c|c|c|}
\hline & N & $\begin{array}{c}\text { M } \\
\text { ean }\end{array}$ & $\begin{array}{c}\text { S } \\
\text { D }\end{array}$ & T & F & Sig \\
\hline Experimental Group & 2 & 1 & 5. & & & \\
\hline Word Part Strategy & 5 & 6.64 & 26 & & & \\
Test & & & & 2. & & P<0.05 \\
\hline Control Group & 2 & 7. & 5. & & & \\
& 5 & 44 & 33 & & & \\
\hline
\end{tabular}

To sum up, the results for Tests A and B demonstrate that word part strategy had a positive effect on students to understand the meaning of unfamiliar words and facilitates L2 vocabulary learning. Furthermore, the better affix knowledge students may have, the more efficient is the learner in facilitating vocabulary acquisition. In this context, learners need 


\section{International Conference on Advanced Research in SOCIAL SCIENCES}

March 7-9, 2019, London - United Kingdom

more time to learn the meaning of affixes and to practice how to re-express meaning of the new formulated words with the aid of the word part strategy. A helpful step, as already suggested, is to offer a dictionary definition of a new word to help students see the connections between the meaning of the word and its constituent word parts. This process can help students to master word part strategy.

\section{Conclusions and Pedagogical Implications for EFL Teachers}

Certainly, the pedagogical implications and practical solutions that can be derived from this study are of great importance. Indeed, it is important for second language learners to acquire useful vocabulary-learning strategies specially word part strategy to reduce the "learning burden" as well as to learn new words by themselves.

Additionally, the findings of the current investigation do confirm the hypothesis stated in the beginning of the study. Unsurprisingly, the findings of the experimental group that outperformed the control group confirmed the hypothesis, which claimed that vocabulary learning will increase after the use of word parts strategy.

Results of the data suggested that word part strategy can assist students in working out most words and increasing their vocabulary. As one of the experimental studies which focuses on the effectiveness of word part strategy, the results of the study demonstrate that the efficiency of word part strategy changes a great deal when considering individual performances. Further research should be carried out in a wider range to investigate the connection between students' English level and the effectiveness of word part strategy. This study is a starting point.

\section{References}

Anderson, J.R (1985). Cognitive psychology and its implications ( $2^{\text {nd }}$ ed). New York: Freeman. Ahari, N, H.et.al. (2014). The Effect of Vocabulary Consolidation Strategy Training on Vocabulary

Learning and Vocabulary Consolidation Strategy Use of Intermediate Iranian EFL Learners. Iran: Islamic Azad University.

Chamot, A. U. \& Kupper, L. (1989). Learning strategies in foreign language instruction. Foreign Language Annual, 22, 13-24.

Chamot, A.U., \& Keatley,C.W. (2004). Learning strategies of students of less commonly taught languages. Paper presented at the 2004 Annual Meeting of the American Educational Research Association, San Diego, CA.

Cohen, A. D. \& Scott, K. (1996). A synthesis of approaches to assessing language learning strategies. In R. L. Oxford (ed.), Language learning strategies around the world: Cross cultural perspectives, $89-108$

Ellis, G. \& Sinclair, B. (1989). Learning to Learn English: a course in learner training. Cambridge: Cambridge University Press.

Ellis, R. (1997). The Study of Second Language Acquisition. Oxford: Oxford University Press. Levingston, E.A.(1979). Second language acquisition: Issues and problems. Interlanguage studies Bulletin,4,pp. 147-160.

Nation, P., \& Waring, R. (1997). Vocabulary size, text coverage and word lists. In N. Schmitt \& M. McCarthy (Eds.), Vocabulary: Description, acquisition and pedagogy (pp. 6-19). Cambridge: Cambridge University Press.

Nation, I. S. P. (2001). Learning vocabulary in another language. Cambridge: Cambridge University Press.

O’Malley, J. M. \& Chamot, A. U. (1990). Learning strategies in second language acquisition. New York: Cambridge University Press. 


\section{International Conference on Advanced Research in SOCIAL SCIENCES}

March 7-9, 2019, London - United Kingdom

Oxford, R. (1985). A new taxonomy for second language learning strategies. Washington DC.: ERIC Clearinghouse on Language and Linguistics.

Oxford, R. (1990). Language learning strategies: What every teacher should know. New York: Newbury House.

Rigney, J. (1978). Learning strategies: A theoretical perspective. In O’Neil, H. F. Jr. (Ed.) Learning Strategies. New York: Academic Press.

Rubin, J.(1975). What the 'good language learner' can teach us. TESOL Quarterly, 9, pp.41-51. Rubin, J. (1981). The study of cognitive processed in second language learning. Applied Linguistics,

2, 117-131.

Rubin, 1987 Rubin, J. (1987). Learner strategies: Theoretical assumptions, research history and typology. In A. Wenden, \& J. Rubin, (Eds.). Learner strategies in language learning. Prentice Hall: New Jersey.

Schmitt, N. (1997). Vocabulary Learning Strategies. In D. N. Schmitt, \& M. McCarthy (Eds.), Vocabulary: Description, Acquisition and Pedagogy (pp. 199-227). Cambridge: Cambridge University Press.

Stern, H. H. (1975). What can we learn from the good language learner. ? Canadian Modern Language Review,31, pp.304-318.

Stern, H. H. (1992). Issues and options in language teaching (edited by Patrick Allen and Brigit Harley). Oxford University Press. 